\title{
The solution of the CRH380 High-speed EMU bogie virtual assembly animation
}

\author{
Cang Song \\ Guidaojiaotong Polytechnic Institute, Shenyang 110023, China
}

Key word: Virtual assembly; Animation; EMU bogie; 3ds Max

\begin{abstract}
Around CRH380 EMU bogie assembly, considering the bogie structural characteristics, grouping, object-oriented modeling, 3D animation, multimedia technology combine design a set of virtual assembly bogie animation method using Pro/E, build three-dimensional parts assembly model and virtual assembly.3ds Max software for animation, mainly to Premiere Pro and photoshop auxiliary software animation processing. Very good solution to the complex products of virtual assembly animation, achievements of popularization value.
\end{abstract}

\section{Introduction}

CRH380 high speed EMU is independent research and development by the Chinese. The idea of dynamic distributed it used is very suitable for the requirements of China's railway transportation, CRH380 EMU's highest speed is $350 \mathrm{~km} / \mathrm{h}$.

This paper around the Production of virtual assembly animation about the CW380 bogie that CRH380 used.Considering several important link, such as bogie 3D modeling, building modeling software and animation software interface, virtual assembly animation making, post-processing and so on. Strive to solve the problems of complex product modeling, animation, optimize the assembly animation effects.

\section{The production plan of virtual assembly animation}

This system uses the Pro/E as 3D modeling tool to build the bogie, then import 3ds Max to make animation assembly. Video animation generated by 3ds Max do not have video special effects such as sound and text annotation. To achieve the ideal animation effects must be through the professional video editing software Premiere Pro for post-processing.

\section{The key technique in the model}

Bogie contains more than 3000 parts, assembly relation is complex, in order to guarantee the accuracy of parts and components in the process of modeling, save the time of modeling and practice often first assembly part wool embryo, characteristics and reference to other parts of the processing to the exact shape of formed parts and positioning, As shown in figure 2a.

In Pro/E, the first step is to assembly of parts, and then for characteristics of the operation.When import the assembly model into 3 ds Max for animation, You will find that the import parts is the original workblank, characteristics of operation can't display, As shown in figure 2b.

Reason is characteristic of parts and components after the operation of Pro/E is considered to be on the outside of the parts, do not modify the original parts level. 


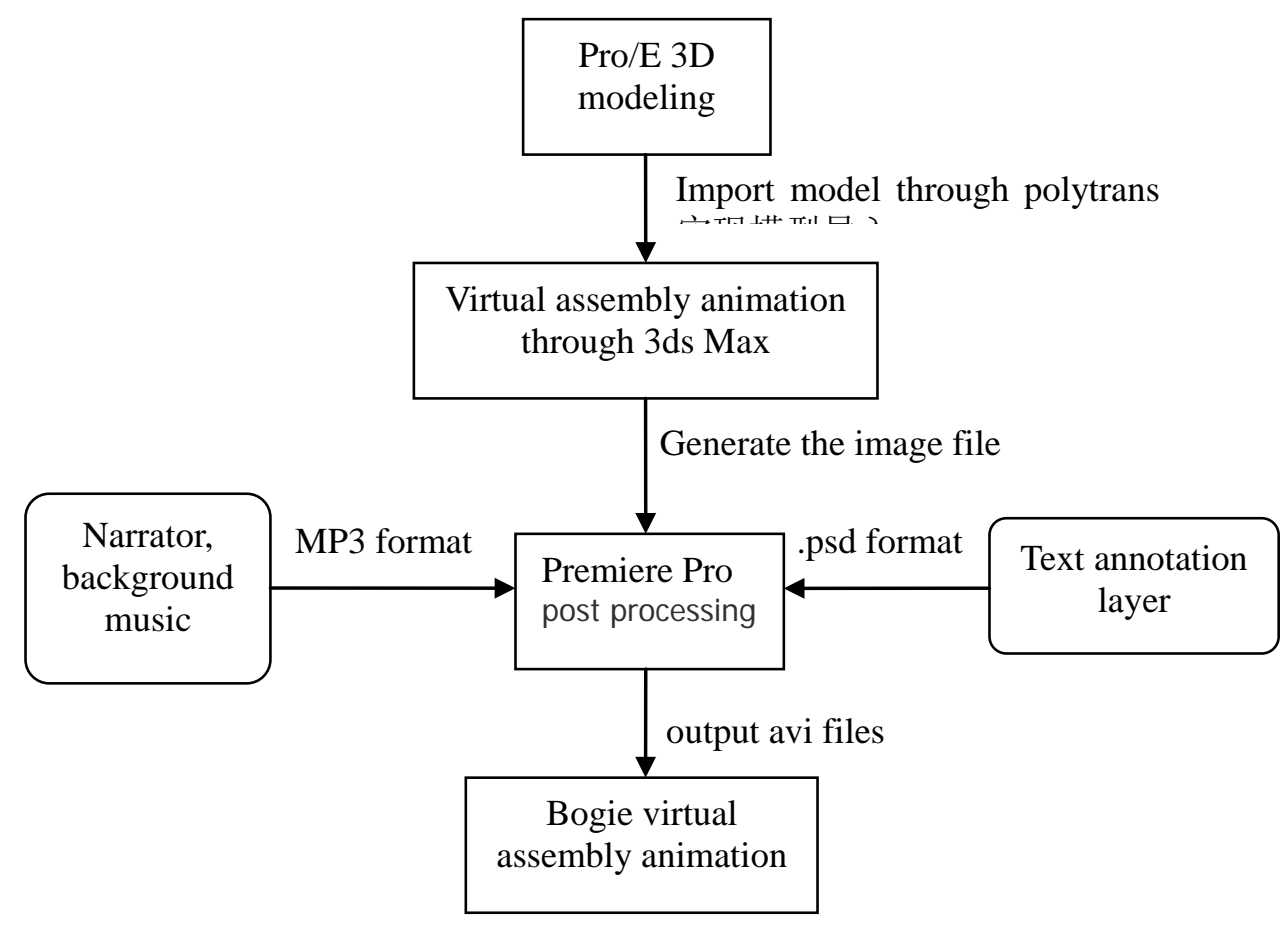

Fig.1 Virtual assembly animation production process flow chart

Solution: need to change the characteristics of the priority, open the "edit custom interface", in the "intersection" cancel "automatic update", selected the parts that need to be cut in the parts list , Set the part's default display level to "parts", confirmed. As shown in figure 2c.

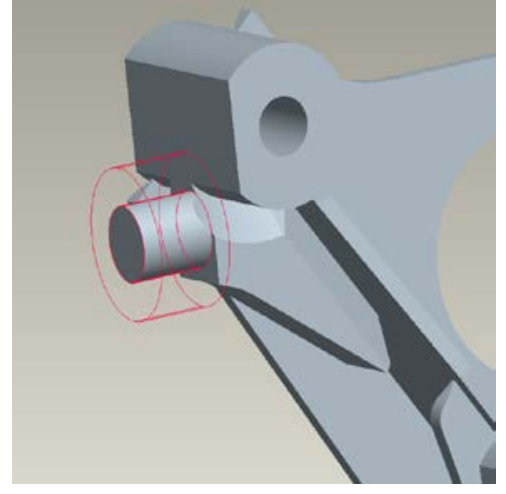

a.Rotate cutting after assembly

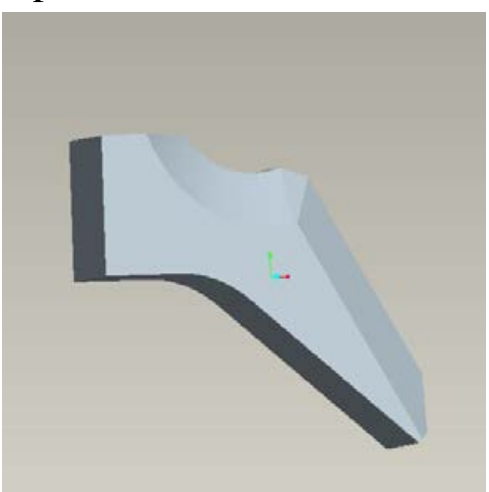

b.In 3 ds Max is the original workblank c. Parts with shear characteristics after setting

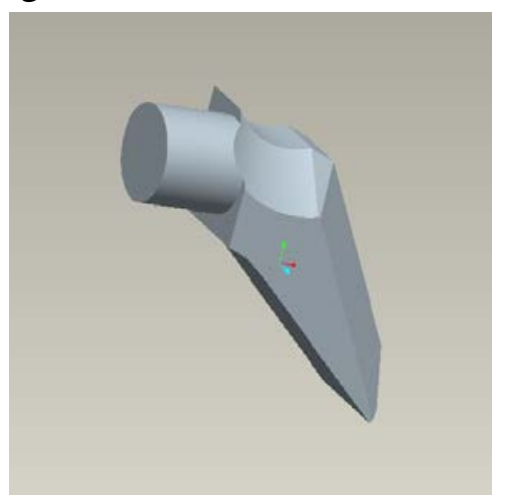

Fig.2 The problem of feature level that modeling in Pro/E

\section{The virtual assembly animation}

The CRH380 EMU bogie are divided into two major categories and ten small category. If the assembly of the ten kinds of bogie respectively do animation, workload will be very large.Considering the structure similar to each type of bogie, the main difference is the parts of different shapes and sizes. So we selected two suitable bogie and set it as a benchmark bogie, and other bogie on this basis.

First of all, the assembly of the selected benchmark bogie, considering the bogie is modular design, here the animation for each module, and then assembled, combined into one scene, to achieve the effect of the whole assembly.

Second, assembling complete bogie in Pro/E model transformed using PolyTrans,that is, we must carry on the virtual assembly of the final result.Record of key frames to determine the final location.Then needed to do is according to the assembly shop of the actual working condition of assembly to the top-down assembly parts. When the benchmark bogie assembly finished, other 
bogie can base bogie as templates, to replace, add, and delete the different parts. Replacement of parts can be connected by a father-son relationship.

The hierarchy of father-son relationship is very important in the animation, connect one object to another object, you can create a father-son relationship, when the transform function on the parent objects at the same time, also through the link relations will change to child objects.Here use the wheel as an example to introduce, CRH380 motor car and trailer wheels of having the same assembly relations and assembly sequence, the difference lies mainly in shape.So when the motor car wheels of the assembly animation production is completed, set it as father-object, Through the father-son connection, Connect the import trailer wheels as son-objects, animation trailer assembly. Finally, the hidden wheel disc and complete the animation.
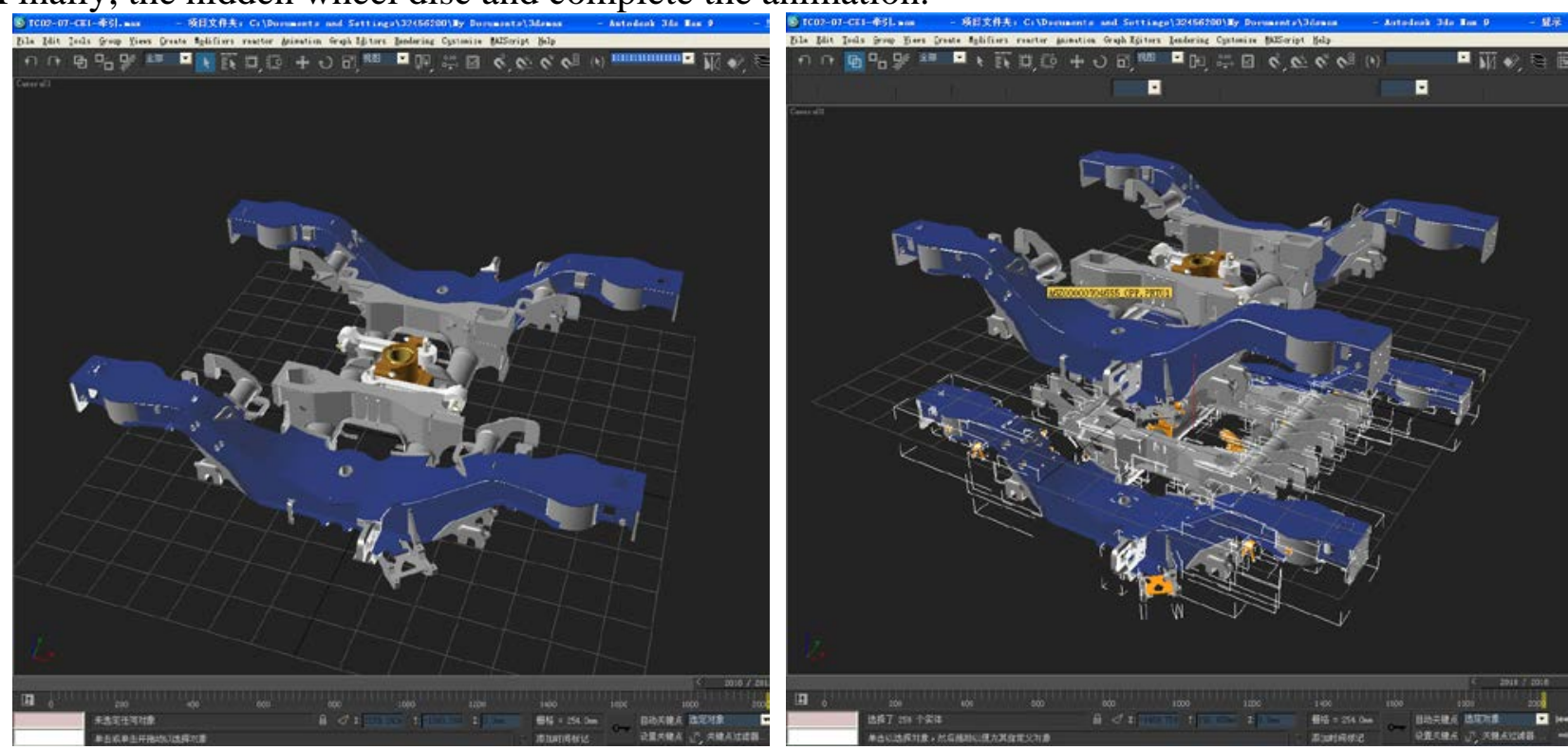

3a. motor traction module

3b.Import trailer frame and Setting relationships connection

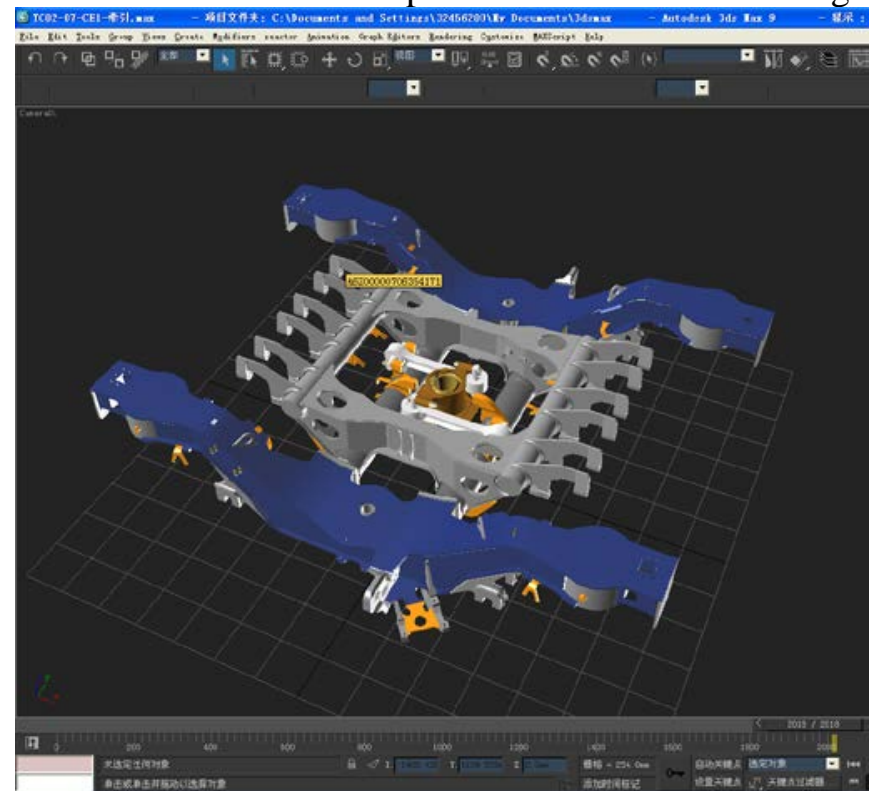

3c.Hidden motor traction module finish tractor traction module architecture

Fig.3 Replacement parts are based on father-son relationships in 3ds Max

\section{Conclusion}

This paper proposed the solution of CRH380 High-speed EMU bogie virtual assembly animation, Analyzed the optimization design idea of EMU bogie virtual assembly animation,Expounds the establishment of the bogie 3D entity model based on Pro/E, Using 3ds Max animation assembly, and the use of Premiere Pro to complete the synthesis of post-production 
video animation principle, Application of the above technologies for CW380 bogie (CRH380 high-speed EMU) for virtual assembly animation production, and eventually built into the CRH380 high-speed EMU bogie multimedia information systems. The design of this group of virtual assembly animation is reasonable, The expression of this animation is intuitively clear, Play is very simple, have very strong practicability, and has been successfully used in changchun railway vehicle co., LTD., education and training. Play is simple, have very strong practicability, and has been successfully used in changchun railway vehicle co., LTD., education and training.The design applies not only to the virtual assembly of high-speed emu bogie, can also be used for other large complex equipment's virtual assembly.

\section{References}

[1] J. F. Wang, J. H. Liu, Y. F. Zhong. A novel ant colony algorithm for assembly sequence planning, Advanced Manufacturing Technology. February,2004:1137-1143

[2] Failli F, Dini G. Ant colony systems in assembly planning: a new approach to sequence detection and optimization. Capri: Proceeding of the 2nd CIRP International Seminar in Intelligent Computation in Manufacturing Engineering. 2000:227-232

[3] J. F. Wang, J. H. Liu, Y. F. Zhong. A novel ant colony algorithm for assembly sequence planning, Advanced Manufacturing Technology, February. 2004:1137-1143

[4] Reinhard Grandl, Virtual process week in the experimental vehicle builds at BMW AG Roboties and Computer Integrated Manufacturing, 2001, 17:65-71

[5] SK.Ong,Y.pang and A.Y.C.Nee,Enabled dynamic tasks planning in Web-based virtual manufaeturing environments,CIRP Annal-Manufacturing Teehnology,2007,56(l):49-52

[6] Run Dang Yang,XiuMin Fan,DianLiang Wu and JuanQi Yan,Virtual assembly Teehnologies based on constraint and DOF analysis,Robotics and Computer-Integrated Manufaeturing,2007,23(4):447-456

[7] Chulho Chung, Qingin Peng, Enabled dynamie tasksplanning in Web-based virtual manufaeturing environments,Computers inIndustry, 2008, 59(l):82-95

[8] Tom C, Johnson Judy M. Vanee., THE USE OF THE VOXMAP POINTSHELL METHOD OF COLLISION DETECTION IN virtual assembly METHODS PLANNING,2001 AsME Design Engineering Technical Conferenees and Computers and information in Engineering Conferenee Vol.2:27th Design Automation Conferenee,2000,1169-1176

[9] Qing-HuiWang, Jing-RongLi, Interactive visualization of eomplex dynamic Virtual environments for industrial assemblies, Computers inindusty, 2006, 57(4):366-377

[10] http://www.okino.com/default.htm 